\title{
The Pharmacology of Chewable Versus Regular Carbamazepine in Chronically Treated Children With Epilepsy
}

\author{
Peter Camfield, Paul Hwang, Carol Camfield, Albert Fraser, Steven Soldin, AK Al-Quadah
}

\begin{abstract}
We report the first comparison of Chewable and Regular Carbamazepine (CBZ) tablets in children with epilepsy. Forty-four children receiving chronic monotherapy $\mathrm{CBZ}$ participated. In month 1 children received regular $\mathrm{CBZ}$; in month 2, the same dose of Chewable CBZ. Once per week fasting predose CBZ and CBZ epoxide serum levels were determined. In a subset of 15 children, at the end of each month serum levels were obtained every 2 hours for 12 hours beginning pre-dose. Standards for CBZ and CBZ epoxide were tested in each centre. Overall, weekly levels showed no consistent differences between the month on chewable CBZ and regular CBZ. Seizure control and rates of reported side effects were similar. In five patients chewable $C B Z$ produced higher peak CBZ levels while five had higher peaks with regular CBZ. In conclusion, regular and chewable CBZ often have unpredictable differences in peak but not trough levels of CBZ suggesting that peak level side effects with one form of CBZ might be alleviated by changing to the other.
\end{abstract}

RÉSUMÉ: Pharmacologie de la carbamazépine à mâcher versus régulière chez les enfants traités de façon chronique pour épilepsie. Nous rapportons la première comparaison de la carbamazépine (CBZ) en tablettes à mâcher et régulière chez les enfants épileptiques. Quarante-quatre enfants recevant de la CBZ en monothérapie chronique ont participé à l'étude. Pendant le premier mois, les enfants ont reçu la CBZ régulière; pendant le deuxième mois, la même dose de $\mathrm{CBZ}$ à mâcher. On a procédé à des déterminations hebdomadaires des taux sériques de CBZ et d'époxyde de CBZ à jeun, avant la prise de CBZ. À la fin de chaque mois, des taux sériques ont été obtenus aux 2 heures pendant 12 heures, commençant avant la première dose, dans un sous-groupe de 15 enfants. Des standards de CBZ et d'époxyde de $\mathrm{CBZ}$ ont été mesurés dans chaque centre. Dans l'ensemble, les taux hebdomadaires n'ont pas montré de différence constante entre le mois où les enfants recevaient de la $\mathrm{CBZ}$ à mâcher et de la $\mathrm{CBZ}$ régulière. Le contrôle des crises et les taux d'effets secondaires rapportés ont été similaires. Chez cinq patients, la CBZ à mâcher a produit des pics plus élevés de $\mathrm{CBZ}$, alors que cinq ont eu des pics plus élevés avec la $\mathrm{CBZ}$ régulière. Donc, la $\mathrm{CBZ}$ régulière et à mâcher ont souvent des différences imprévisibles dans le pic mais non dans les niveaux courants de CBZ suggérant que les effets secondaires lors du pic avec une présentation de CBZ pourraient être atténués en changement à l'autre présentation.

Can. J. Neurol. Sci. 1992; 19: 204-207

Carbamazepine ( $\mathrm{CBZ}$ ) is one of the most frequently used antiepileptic medications in children. ${ }^{1}$ It exists in several formulations including a regular tablet, a chewable tablet, a suspension (in the U.S.A.), and a controlled release form (in Canada and other countries). There have been no studies comparing the pharmacology of the regular tablet with the chewable tablet in chronically treated children. In this study we report a multicentre study that compares the chewable and regular form of the drug.

\section{METHODS}

The study was carried out in 5 centres across Canada. The study was approved by the institutional review board in each centre and informed consent was obtained. Children aged less than 16 years were eligible, if they had epilepsy and had been treated for at least 6 months with $\mathrm{CBZ}$ as monotherapy. Patients were excluded who received other medications on a regular basis or had any progressive systemic or neurologic diseases.

From the IWK Children's Hospital, Department of Pediatrics, Dalhousie University, Halifax (PC, CC); the Division of Neurology, the Hospital for Sick Children, University of Toronto, Toronto (PH, AA-Q); the Department of Toxicology, Victoria General Hospital, Halifax (AF); and the Children's Hospital National Medical Center, Department of Laboratory Medicine, Washington, D.C. (SS)

Received July 15, 1991. Accepted in final form December 2, 1991

Presented in part at the Canadian Congress of Neurologic Sciences, Quebec, June 1989

Reprint requests to: Dr. Peter Camfield, IWK Children's Hospital, Box 3070, Halifax, Nova Scotia, Canada B3J 3G9 
The study was divided into 2 , one month, study periods. In the first month the children received regular CBZ (Tegretol TM). They received their usual daily dose for 4 consecutive weeks with fasting CBZ and CBZ 10-11 epoxide serum levels obtained weekly. At the end of the first 4 weeks in two centres only, study patients spent 12 hours at the hospital between $8 \mathrm{AM}$ and 8 PM. Blood was obtained for CBZ and CBZ 10-11 epoxide levels every 2 hours with the first sample before the morning dose of CBZ.

In the second month all study patients were switched to the identical dose of chewable CBZ (Tegretol Chewtabs TM) with the same daily dosing schedule. Again AM fasting serum levels were obtained weekly for 4 further weeks. At the end of the second month the same children who had 12 hour curves obtained on regular $\mathrm{CBZ}$ underwent the same 12 hour serum sampling following chewable CBZ.

CBZ and $C B Z$ 10-11 epoxide levels were determined using high pressure liquid chromatography. ${ }^{2.3}$ For the two centres performing 12 hour curves standard CBZ concentration samples were analyzed in the two laboratories for comparison of consistency of technique. The results were essentially identical (less than $5 \%$ variation).

In one of the centres performing the 12 hour curves, samples from 2 patients were split and the carbamazepine 10-11 epoxide levels were measured in each of the two laboratories for evidence of consistency. Again there were no significant measurement differences between centers.

Compliance was assessed by weekly pill counts.

\section{Results}

Forty-four patients, 23 boys and 21 girls entered the study. Three patients dropped out ( 1 on regular CBZ and 2 on chewable CBZ) for reasons unrelated to medication side effects. The

Table 1: Total Number of Seizures on Regular vs Chewable Carbamazepine

\begin{tabular}{lcc}
\hline \hline \multicolumn{1}{c}{$\begin{array}{c}\text { Total Seizures } \\
\text { Regular Carbamazepine }\end{array}$} & $\begin{array}{c}\text { Total Seizures } \\
\text { Chewable Carbamazepine }\end{array}$ \\
\hline Seizure Type & & \\
$\quad$ Complex Partial & 8 & 4 \\
Simple Partial & 0 & 1 \\
Generalized & & \\
$\quad$ Tonic Clonic & 10 & 7 \\
Absence ** & 15 & 3 \\
Uncategorized & 5 & 5 \\
\hline
\end{tabular}

** patients with absence had more than one seizure type and received an anti-absence medication plus carbamazepine

Table 2: Mean Fasting Serum Levels for all Patients (obtained weekly) in micromoles/litre

\begin{tabular}{lcc}
\hline \hline & CBZ Serum Level & $\begin{array}{c}\text { CBZ 10-11 } \\
\text { Epoxide Serum Level }\end{array}$ \\
\hline Regular CBZ & $27.5 \pm 14.9$ STD & $5.8 \pm 2.2$ STD \\
Chewable CBZ & $26.3 \pm 8.0$ STD & $4.9 \pm 1.9$ STD \\
\hline
\end{tabular}

average age of patients was $11 \pm 3$ (STD) years. The average daily dose was $565 \pm 188 \mathrm{mg}$ (range $200-1100 \mathrm{mg} /$ day).

The total number of seizures reported by patients during the first and second months was essentially the same (Table 1 $\mathrm{p}=\mathrm{NS}$, paired $\mathrm{t}$-test .

Side effects were noted with similar frequency with the chewable and regular CBZ. Tiredness and drowsiness were reported in 4 patients all on regular CBZ, while $4 / 5$ patients with reported behaviour disturbance received chewable $\mathrm{CBZ}$.

Mean weekly fasting CBZ and CBZ 10-11 epoxide serum levels were virtually identical between the two study months. There were no significant trends noted across the visits (Table 2).

Weekly pill counts showed excellent compliance with only 3 patients showing a single week with $<80 \%$ of prescribed pills taken.

Twelve hour curves were carried out in 15 children all of whom received $\mathrm{CBZ}$ monotherapy. Their average daily dose was $13.5 \mathrm{mg} / \mathrm{kg} /$ day (range $4.4-20.6 \mathrm{mg} / \mathrm{kg} /$ day). Ten children received twice daily dosing and five children, three times daily dosing.

When the data were combined for all patients the 12 hour curves were very similar for regular versus chewable CBZ ( $\mathrm{P}=\mathrm{NS}$ for paired $\mathrm{t}$-tests for each sampling time).

For each case with 12 hour curves, the following were compared for the two 12 hour curves - Cmin, Tmax, Cmax, area under the curve (times $0-12$ hours), and peak/trough ratio (Table 3). The mean values of each of these measurements did not appear to show significant differences between regular and chewable CBZ (paired t-tests). Nonetheless, despite the lack of difference in overall mean values, for some individual patients the differences were quite marked.

Among the 10 patients with twice daily dosing, there were 5 with clinically important higher peak CBZ levels with chewable than with regular CBZ by an average of $26 \%$. The curve for one such patient is illustrated (Figure 1).

Two children on twice daily dosing had higher peak CBZ serum levels with regular than with chewable CBZ, by an average of $17 \%$.

Among the 5 patients on 3 times a day dosing regimens, 3 showed higher peaks with regular CBZ, averaging $26 \%$ higher. The curve for one such patient is illustrated (Figure 2).

Table 3: Mean Serum Levels for 12 Hour Curves in Micromoles/L (STD)

\begin{tabular}{lrrrrrr}
\hline \hline & Cmin & Tmax & Cmax & \multicolumn{1}{c}{ Peak/Trough } \\
Ratio & \multicolumn{1}{c}{ Auc } \\
\hline Reg CBZ & $27(6.7)$ & 6 & $(2.3)$ & $37(8.3)$ & $1.39(0.2)$ & $376(88)$ \\
Chew CBZ & $24.3(5.2)$ & $5.6(2.3)$ & $36(70)$ & $1.5(0.32)$ & $367(125)$ \\
Reg Epox & $4.8(1.3)$ & $6.4(4)$ & $6(1.4)$ & $1.3(0.15)$ & \\
Chew Epox & $4.1(1.5)$ & $5.6(2.6)$ & $5.6(2.1)$ & $1.4(0.15)$ & \\
\hline
\end{tabular}

Reg $C B Z=$ serum $C B Z$ level when patients received regular $C B Z$

Chew $\mathrm{CBZ}=$ serum $\mathrm{CBZ}$ level when patients received chewable $\mathrm{CBZ}$

Reg Epox = serum CBZ 10-11 epoxide level when patients received regular $\mathrm{CBZ}$

Chew Epox = serum CBZ 10-11 epoxide level when patients received chewable CBZ

$\mathrm{Cmin}=$ minimum serum level (predose trough level)

Cmax $=$ maximum serum level (peak level)

Auc $=$ area under the 12 hour serum level curve (time 0-12 hours) 


\section{CHEWABLE VS REGULAR CBZ \\ 2 DAILY DOSES}

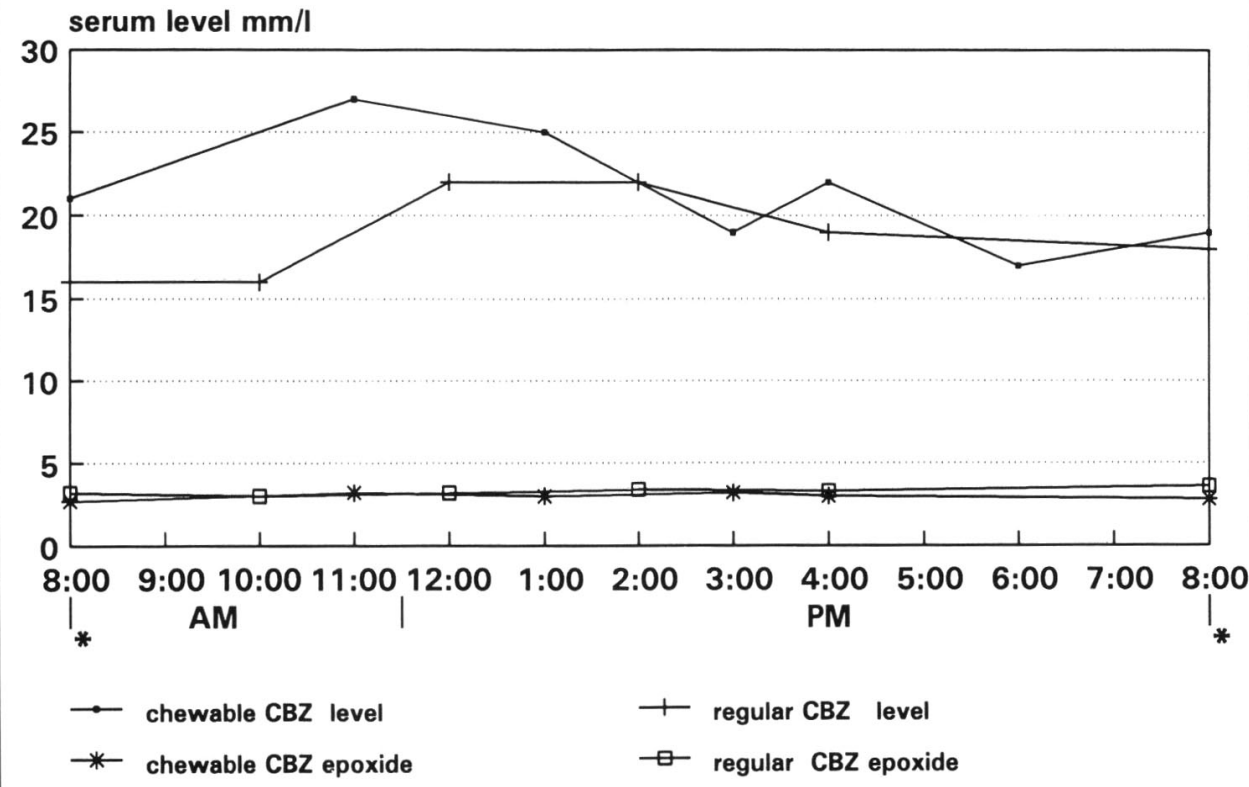

* cbz $200 \mathrm{mg}$
Figure I - 12 hour curves for one patient on twice daily dosing.

\section{CHEWABLE VS REGULAR CBZ 3 DAILY DOSES}

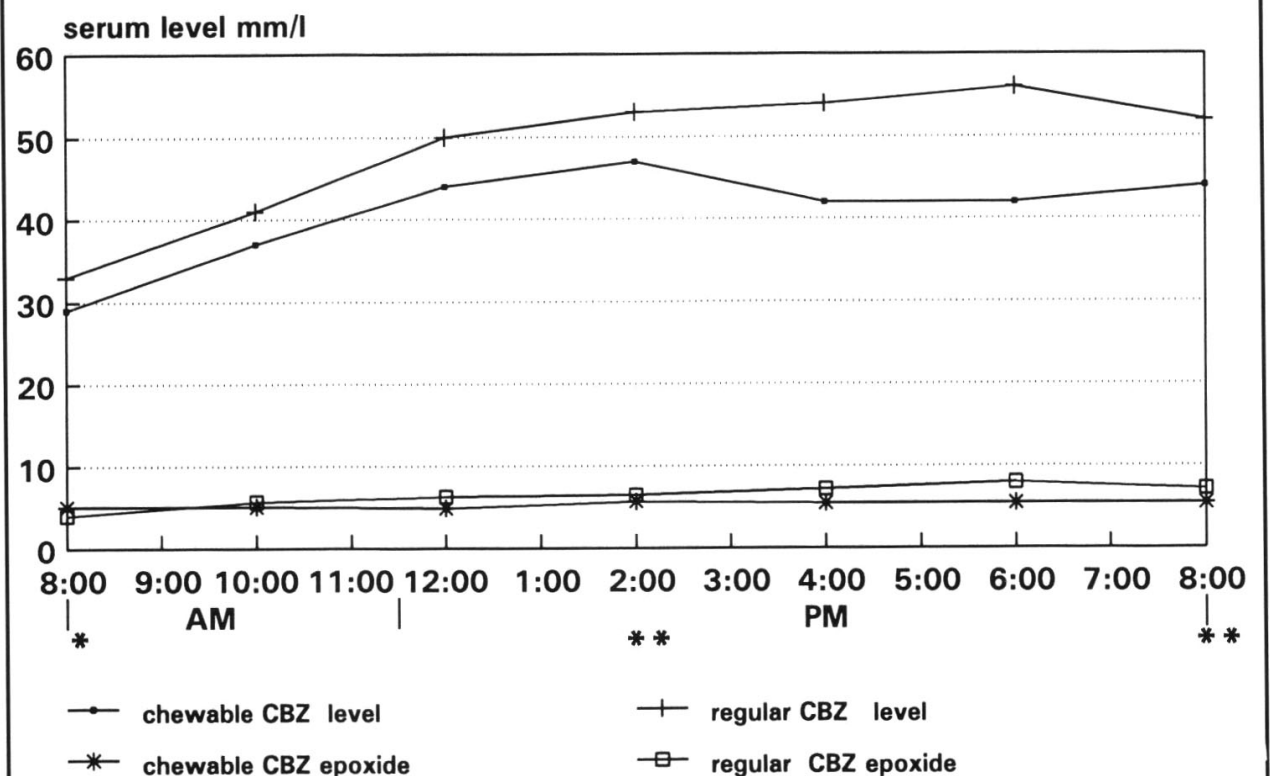

* cbz $200 \mathrm{mg}$

* * cbz $300 \mathrm{mg}$
Figure $2-12$ hour curves for one patient on three times/day dosing. 


\section{Conclusion}

This study suggests that, on average, the pharmacokinetics of chewable and regular CBZ are very similar in chronically treated children with epilepsy. Similarities include bioavailability (judged by mean values of area under the curve during 12 hours serum level profiles) and half life (judged by mean values for AM fasting levels). The efficacy of these two formulations of CBZ in this group of children with epilepsy appeared to be essentially equal.

The mean values do, however, obscure the findings for individual patients. Five of our patients on twice daily dosing had higher peak serum levels on chewable CBZ - a difference that may be clinically important. On the other hand, three children on three times a day dosing had a similar difference with the higher peaks with regular CBZ. It is unclear whether such variations are related to fundamental differences in the way the two preparations are absorbed and/or metabolized by these individual patients. It is possible that patients on the same formulation of CBZ everyday have great variation of peak levels depending on diet or other factors. We are unaware of other studies with CBZ that have repeated 12 hour curves in the same patient. Diet, however, may change the absorption pattern of other anticonvulsant drugs. For example tube feeding may inhibit the absorption of phenytoin. ${ }^{4}$

Only one other published study has examined the difference between regular and chewable CBZ. ${ }^{5}$ Maas et al. studied 10 adult volunteers for 48 hours after a single dose of $200 \mathrm{mg}$ of $\mathrm{CBZ}$. On one occasion they took regular $\mathrm{CBZ}$ and on another occasion chewable CBZ. These volunteers were naive to $\mathrm{CBZ}$ and would not be expected to have any of the P450 enzyme induction noted in chronic use. Maas noted greater bioavailability and higher peak levels with the chewable CBZ - results that resemble five of our cases noted above.
Careful psychological studies have found that peak levels of CBZ may be associated with diminished cognitive performance. ${ }^{6}$ Our study would suggest that high peak levels are not more likely to occur with regular than chewable CBZ. However, in individual patients with peak level side effects, there may be enough difference to warrant a switch of one form of CBZ to another. Our study does not address the potential value of controlled release $\mathrm{CBZ}$ although we did find that peak levels of CBZ with chewable or regular CBZ average $40-60 \%$ higher than predose levels.

In summary, our study suggests that, in general, chewable and regular CBZ have very similar pharmacokinetics but individual patients may show some differences.

\section{ACKNOWLEDGEMENT}

Supported in part by a grant from Ciba Geigy Canada Lid. We thank Drs. James Jan (Vancouver), George Hinton (London) and Ehore Gauk (Edmonton) for their collaboration by entering patients into the study and sharing their results.

\section{REFERENCES}

1. Dodson WE. Carbamazepine efficacy and utilization in children. Epilepsia 1987; 28 (Suppl 3): s17-s24.

2. Soldin SJ. High performance liquid chromatographic analysis of anti-convulsant drugs using radial compression columns. Clin Biochem 1980; 13: 99-101.

3. Fraser AD, Camfield PR, Weaver D. Clinical pharmacokinetic features of severe carbamazepine poisoning. Clin Biochem 1987; 20: 296.

4. Bauer LA. Interference of oral phenytoin absorption by continuous nasogastric feedings. Neurology 1982; 32: 570-572.

5. Maas B, Garnett WR, Pellock JM, Comstock TJ. A comparative bioavailability study of carbamazepine tablets and a chewable tablet formulation. Ther Drug Monit 1987; 9: 28-33.

6. Aldenkamp AP, Alpherts MC, Moerland MC, Ottevanger N, Van Parys JAP. Controlled release carbamazepine: cognitive side effects in patients with epilepsy. Epilepsia 1987; 28: 507-514. 